NBER WORKING PAPER SERIES
CONTRACTIONARY DEVALUATION, AND DYNAMIC ADJUSTMENT
OF EXPORTS AND WAGES

\author{
Felipe Larrain \\ Jeffrey Sachs
}

Working Paper No. 2078
NATIONAL BUREAU OF ECONOMIC RESEARCH 1050 Massachusetts Avenue
Cambridge, MA 02138
November 1986

\begin{abstract}
We would like to thank Andy Abel, Barry Eichengreen and Andreu Mas-Colell for very helpful suggestions. Financial support from Universidad Catolica de Chile is gratefully acknowledged. The research reported here is part of the NBER's research program in International Studies. Any opinions expressed are those of the author and not those of the National Bureau of Economic Research.
\end{abstract}




\title{
Contractionary Devaluation, and Dynamic Adjustment of Exports and Wages
}

\begin{abstract}
Recent macroeconomic models of developing countries have emphasized the possibility of contactionary devaluations, stressing that domestic aggregate demand is likely to be reduced by the devaluations while aggregate supply may respond only slowly to the change in relative prices brought about by the devaluation. These results have been obtained in static models. In this paper we add wage and export-sector dynamics to the models of contractionary devaluation, and show that the effects which produce contractionary devaluations in the short term can produce limit cycles in the long run. The economy never returns to long-run equilibrium following a devaluation, but rather moves with fixed periodicity through successive phases of boom and bust.
\end{abstract}

Felipe Larrain

Instituto de Economia Pontifica Universidad Catolica de chile Cas. 274-V, Correo 21 Santiago CHILE
Jeffrey Sachs

Department of Economics

Harvard University

Cambridge, MA 02138 


\section{Introduction.}

Exchange rate changes have important and multiple effects on economic activity. When currency parities are fixed, as it happens in most developing countries, devaluation becomes a key policy option for the authority. The crucial task is then to assess the impact of a devaluation both on the external payments position of the country, which is likely to improve, and on the level of economic activity, a more controversial issue. International institutions typically recomnend exchange rate increases as a way of coping with "fundamental" imbalances in the countries' external situation, while at the same time domestic authorities are reluctant to devalue.

Early economic approaches to this problem were centered around the well-known Marshall-Lerner condition, initially stated in a partial equilibrium framework in which the trade account was in balance and substantial unemployment existed. In the early fifties this condition was extended to a general equilibrium, open-econonomy Keynesian multiplier scenario which did not signifficantly affect the previous result. Subsequent developments considered situations of initial trade imbalance, as empirical evidence overwhelmingly suggested. On the other hand, the absorption approach stressed the trade balance as the result of an aggregate income-expenditure relationship, an appropriate framework to study the distribution effects coming from a devaluation.

Krugman and Taylor (1978) develop a general equilibrium model integrating income redistribution effects of a devaluation from an initial trade imbalance situation. Their key conclusion is that a devaluation has contractionary 
effects on domestic income, while improving the trade balance.

This paper adds a dynamic structure to their model by allowing sluggish adjustment of wages through a traditional phillips curve. Under these conditions a devaluation is again contractionary, but this time the system is unstable due to the interaction of a demand determined home goods sector, a fixed supply of exports and the Phillips curve. After the exchange rate increase there are no forces in the model to stop the downward trend.

Available empirical evidence suggests a more realistic scenario where exports respond to price incentives in addition to wages. In this case the export response is not only expansionary, but also pushes the system towards stability. It is possible, however, that even with a large long run elasticity of exports with respect to wages, the economy does not smoothly return to equilibrium after a devaluation. If the export sector does not react fast enough to a devaluation the economy is unstable around the steady state. Nonetheless, even in this case it may be possible to show that a Poincare-Bendixson limit cycle exists, thus stopping the downward trend of the economy. Under some circumstances the existence of a Hopf bifurcation cycle may also occur. At least one of these cycles is stable.

The paper starts with a brief review of devaluation theory and evidence, placing Krugman and Taylor in its appropriate relation to it. The next section introduces wage dynamics and studies the stability properties of the model, while section 4 considers both wage and export adjustment. Finally, section 5 states the main conclusions. 
2. A brief review on devaluation theory and evidence.

Early analyses of devaluation were centered around the well-known Marshall-Lerner condition' stating that a devaluation will improve the trade balance as long as

$$
\eta_{n}+\eta_{x}^{*}>1
$$

where $\eta_{\mathrm{m}}$ is the home country's price-elasticity of demand for imports and $\eta_{x}^{*}$ is the world's price-elasticity of demand for the country's exports.

This condition was derived starting from a scenario in which the home country specializes in the production of an exportable good whose supply in terms of domestic currency is infinitely elastic. As a corollary, the devaluation brings about a one-to-one deterioration in the terms of trade if the country is a price taker for imports. The trade account is assumed in equilibrium at the moment of the devaluation.

Further theoretical developments come with the work of Robinson $(1947)^{2}$ and Hirschman (1949), who investigate the effects of a devaluation starting from a trade imbalance. Under these conditions it becomes necessary to distinguish between the trade balance expressed in domestic currency and its counterpart in foreign currency, since they will not necessarily move in the same direction. The practical relevance of this analysis is immense since most -if not all-countries devalue their currency in the face of a trade deficit. What

1Marshall (1923), Appendix J. Lerner (1944), Chapter 28, p. 377-380.

2Robinson (1947), Part III "The foreign exchanges", P. 142-143. 
matters then to solve the payments problem is the foreign-currency balance, which is more likely to improve. However, it is the trade balance expressed in domestic currency which is relevant in terms of aggregate demand; this one is more likely to deteriorate. Thus, a not uncommon outcome of a devaluation in this scenario is a contractionary effect on domestic income coupled with an improvement in the foreign currency denominated trade balance. 3

Intuition for this result may be strengthened by thinking of a devaIuation as having two types of effects: (i) a valuation effect on the 1nitial quantities of imports and exports at the higher exchange rate, and (ii) a quantity effect, given by the responsiveness (i.e. the elasticities) of imports and exports to the price change, evaluated at the previous exchange rate. When trade is initially balanced, the higher cost of imports exactly cancels out with the additional export revenue (at the original quantities). The valuation effect is nil in this case and only the quantity effect is left. But when the country starts from a trade deficit the valuation effect operates towards a deterioration in the domestic currency denominated balance and thus contracts internal demand for domestic goods (unless there is an offsetting effect coming from a reduction in savings).

The elasticities approach was originally stated as a partial equilibrium relationship involving only the markets of imports and exports. Harberger (1950) and Laursen and Metzler (1950) adequately restate it by considering the

${ }^{3}$ This point has been stressed, among others, by cooper (1971a). 
general equilibrium effects coming from the Reynesian open-economy multiplier. The modified relationship, however, presents the same qualitative result as before: an improvement in the trade balance following a devaluation requires that the sum of the relevant price elasticities exceeds one.

Sidney Alexander (1952) called attention to the fact that if a devaluation was to improve the current account it had to reduce in some way expenditure relative to income. His insight, coming from the national income identity, is the well known Keynesian "absorption approach". Looked in this perspective, the potential terms of trade deterioration arising from a devaluation was expected to reduce savings for a given level of income and thus to deteriorate the current account; this is better-known as the Laursen-Metzler effect. Recent contributions by Obstfeld (1982), Sachs (1981, 1982a) and Svensson and Razin (1983) have pointed out that the direction of the effect on the current account is ambiguous, and depends on the terms of trade deterioration being transitory or permanent.

Dornbusch (1976) studies the conditions under which the absorption approach can be properly integrated with the earlier elasticities approach. He also concludes that, starting from trade balance, if the terms of trade remain unchanged after the devaluation the commercial balance can not deteriorate. Distribution effects can also play a role on expenditure determination following exchange rate movements. In particular, Diaz-Alejandro (1963) has argued that a devaluation is likely to redistribute income from workers to capitalists. If the former group has a higher marginal propensity to consume than 
the latter one, expenditure will go down and so will output in a demand determined model. The classical example is the Argentinian devaluation of 1958 which, according to Diaz-Alejandro (1965), importantly accounts for the 1959 recession in that country through its redistribution effect from workers to landowners.

A different line of argument has been stressed in the monetary approach to the balance of payments, 4 where a devaluation is analyzed through its effects on the money market. More precisely, an exchange rate increase will provoke a stock excess demand for money; with passive monetary policy, the only way to go back to equilibrium is by running balance of payments surpluses whose effects on the money stock are assumed not to be sterilized by the authority. This type of models, based in a line of thought dating as far back as David Hume (1752), have almost always been carried out under full employment and with money as the only asset. 5 When nontradeable goods are introduced in this framework the devaluation has real effects, but only in the short run. The link is formally made by Dornbush (1974) using the ad-hoc expenditure function, later grounded in optimizing behavior by Dornbusch and Mussa (1975). The initial excess demand for money provoked by the devaluation is translated into an excess of income over expenditure which pushes downward the relative price of nontradeable goods, thereby causing consumption and production switches and a surplus in the balance of payments. The effect lasts only while there is unsatisfied ex-

${ }^{4}$ For a survey on the monetary approach see Johnson (1977).

5 An extension to more than one asset is found in Dornbusch (1975) in what could be called a portfolio approach rather than a monetary approach. 
cess demand for money, and so it dissappears through time. The only way in which a devaluation can have long run effects (other than reserve accumulation) is in the presence of wage/price stickiness, where it serves to simultaneously achieve internal and external balance. 6

Krugman and Taylor (1978), hereafter referred to as $K-T$, pursue a structuralist approach for an economy composed of three types of goods: exportables, importables and nontradeables. A Reynesian stand is taken in the home good market, where output is demand determined. Imports are neither produced nor consumed domestically but rather used as intermediate inputs in the production of the home good and exports are in fixed supply. In this sense, the Keynesian and structuralist approaches towards exports can be considered as two extremes, with neoclassic analysis (the one used in the monetary approach, if any) standing somewhere in the middle.

Two crucial features of $K-T$ have been borrowed from the earlier contributions discussed in this section: the existence of two groups of agents with different marginal propensities to consume and the starting point of the economy from a trade deficit.

An extension of $K-T$ to account for substitutability both in production and in consumption is provided by Hanson (1983). His results challenge those of $K-T$ regarding the effect of a devaluation on domestic income and the balance of payments. Indeed, $K-T$ 's conclusions come as no surprise in view of

${ }^{6}$ See Dornbusch (1974). 
their assumptions which close any possible channel through which a devaluation could be expansionary.

Empirical work on the effects of devaluation does not abound. Cooper (1971b), analyzing the short run effects (after one year) of 24 devaluations for the period 1953-66,"...including most of the major devaluations by developing countries in the early 1960s...n7 finds that in nearly three-fourths of the cases the trade balance improved. He also reports a negligible impact of the exchange rate change on the terms of trade and a response of domestic wages and prices that falls short of the currency depreciation. Connolly and Taylor (1976) study 18 devaluation episodes in 14 mostly developing countries for the period 1959-70. They conclude that exchange rate increases appear on average not to have a significant effect on economic activity while at the same time generally improving the balance of payments. Krueger (1978) analyzes 22 devaluations in 10 third world countries to conclude that only in three cases it was followed by a signifficant recession.

More recently, Gylfasson and Schmid (1983) have developed and tested a one sector model in which output is determined by the interaction of supply and demand. A devaluation influences the former through the cost of intermediate inputs and the latter through substitution, income and real balance effects. The results for a group of 10 countries $(5$ industrialized and 5 developing) show a contractionary effect of an exchange rate increase only in 2 cases (India and

${ }^{7}$ Cooper $(1971 \mathrm{~b})$, p. 20. 
the U.K.). Larrain (1985) presents evidence indicating that medium to large devaluations tend to decrease the product wage, at least in the short run, except in economies undergoing strong and steady depreciation of their currencies, and that employment in the tradeables sector is a decreasing function of the product wage.

One of the reasons for the lack of empirical work on devaluations no doubt arises from the difficulty of separating it from other parallel influences in the economy. In particular, exchange rate changes in developing countries are usually accompanied by liberalization and/or stabilization attempts, as stressed by Cooper (1971b) and thoroughly studied in the NBER project headed by Rrueger and Bhagwati.

3. Contractionary devaluation and wage Adjustment.

The original $\mathrm{R}-\mathrm{T}$ model, with its notation kept as much as possible for comparative purposes, is stated below:

(1) $P_{h}=\left(a_{1 h} w+a_{m h} P_{m}\right)(1+z)$

(2) $P_{\mathbf{X}}=\left(1-t_{\mathbf{x}}\right) P_{\mathbf{X}}{ }^{*} e$

(3) $P_{m}=\left(1+t_{m}\right) P_{m}$

(1)-(3) are the price formation equations, with tax-corrected purchasing power parity for tradeables and mark-up pricing for the home good, where $P_{h}=$ price of the home good, $a_{1 h}=$ amount of labor to produce a unit of the home 
good, $a_{m h}=$ amount of the imported input to produce a unit of the home good, w $=$ nominal wage, $z=f$ ixed mark-up over costs, $\mathbf{p}_{\mathbf{x}}=$ internal price of exports, $t_{\mathbf{x}}=$ ad-valorem tariff on exports, $\mathbf{P}_{\mathbf{x}}{ }^{*}=$ world price of exports, $\mathbf{e}^{=}$norinal exchange rate, $P_{m}=$ internal price of the imported input, $t_{m}=$ ad-valorem tariff on the imported input, and $\mathrm{P}_{\mathrm{m}}{ }^{*}=$ world price of the imported input.

(4) $Y_{w}=\left(a_{1 h} H+a x^{X}\right) w$

(5) $Y_{r}=z\left(a_{1 h} w+a_{m h} P_{m}\right) H+\left(P_{x}-a_{1 x^{w}}\right) X$

$Y_{w}$ and $Y_{Y}$ define the incomes of workers and capitalists respectively, $H$ are the units of the home good and $X$ stands for the volume of exports. $Y_{Y}$ is derived both from a fixed mark-up over cost in domestic goods production and from profits in exports. With this latter sector in fixed supply output can only vary through home goods which are demand determined, as specified below.

(6) $H=C_{W}\left(Y_{w} / P_{h}\right)+C_{Y}\left(Y_{Y} / P_{h}\right)+I(r)+G$

Imports (M) are intermediate goods used exclusively in the production of nontradeables, and thus

(7) $M=a_{m h} H$

Many empirical studies, as well as casual evidence, have shown the existence of some stickiness in the behavior of nominal wages for different countries and sample periods. But sticky wages are not the same as fixed wages, 
as $\mathrm{K}-\mathrm{T}$ assume, and once we depart from the very short run 1 t is necessary to provide a mechanism for wage adjustment.

Doing so will imply adaing a dynamic structure to an otherwise static model. In the new scenario wages will be sticky in the sense that they will not react instantaneously to clear the labor market; rather, they will adjust downwards under conditions of excess supply in the labor market and upwards when excess demand prevails. This defines a Phillips curve type equation which is specified below

$$
\begin{array}{rlrl}
\text { (8) } w^{*} & =\phi\left(L-L^{*}\right) & \text { if } w & \geqslant 0 \\
& =\max \left[0, \phi\left(L-L^{*}\right)\right] & \text { if } w=0 \\
& \text { with } \phi^{\prime} \geqslant, \phi^{\prime}=0, \phi(0)=0
\end{array}
$$

where $\dot{w}=d w / d(t i m e)$

$I=$ current level of employment

$L^{\star}=$ "natural" or noninflationary employment level

Inflationary expectations are not included in (13) because the exchange rate and world prices are assumed to be fixed and thus there is no inflation in the long run. We further assume no population growth and a totally inelastic labor supply; with this $L^{*}$ becomes a constant. 8

The model consists now of equations (1)-(8). It is clear that in this modified scenario the immediate effect of a devaluation can not be diffe-

${ }^{8}$ For the effects of labor supply responsive to the wage rate in a static version of this model see Hanson (1983). 
rent than in $\mathrm{K}-\mathrm{T}$ since nominal wages are fixed on 1mpact. Rather, we will be $1 \mathrm{n}-$ terested in studying the dynamic properties of the system. In particular, stability requires that $\dot{d w} / d w / 0$, since the model has only one differential equation. We notice that

$$
\dot{d w} / d w=(\dot{d w} / d L)(d L / d w)=\phi^{\prime} a_{I h}(d H / d w)
$$

our equation for output determination in the home good market is obtained by replacing (1)-(5) and (7) in (6). Using this, and after some computations, we can express (9) in terms of the underlying parameters of the model as

$$
\begin{aligned}
& \text { (10) } \frac{d \dot{w}}{d w}=\frac{\phi^{\prime} a_{I h}(1+z)}{D_{0} P_{h}}\left\{\left(\gamma_{w}-\gamma_{I}\right) K_{0}{ }^{\prime}+a_{I h}\left(\gamma_{w} M P_{m}^{*} e-Y_{I} X P_{X}^{*} e\right)\right. \\
& \left.+a_{I h}\left(\gamma_{w} t_{m} M_{m}{ }^{\star} e+Y_{I} t_{X} X P_{X}{ }^{*} e\right)\right\}
\end{aligned}
$$

where $R_{0}{ }^{\prime}=a_{1 \times} \times a_{m h} P_{m}{ }^{*} e$

$$
\begin{aligned}
D_{O}= & \left\{a_{1 h} w\left[\left(1-Y_{w}\right)+z\left(1-Y_{Y}\right)\right]+a_{m h} P^{*} m\left(1+t_{m}\right)\left[1+z\left(1-Y^{r}\right)\right]\right\} \\
& \text { Expression }(10) \text { is clearly positive under the original } K-T \text { assump- }
\end{aligned}
$$
tions, rendering the model unambiguously unstable.

The intuition for this instability result goes as follows. The devaluation, by decreasing real wages, depresses demand for home goods and hence output and employment. But the increase in unemployment, through the Phillips curve, drives downward the nominal wage and with it the real wage. This further decreases demand and there are no forces in the model to stop this downward trend. Formally, we can notice that the sign of $d \dot{w} / d w$ is exactly the opposite as 
that of dH/de; thus, whenever a devaluation is contractionary instability is also present.

Graphically we can plot the equation of wage dynamics and the general equilibrium relationship between employment and wages from the home good market (HH) in (w,L) space, as presented in figure 1. The initial assumption about domestic goods being demand determined implies that the economy will always lie in some point of the HH schedule, with the long run equilibrium also requiring wages to be at rest (point E). The preceding discussion tells us that if any shock (e.g. a devaluation) moves the economy away from steady state, forces in the model will further move us away from equilibrium. This explains the divergent arrows being drawn through $\mathrm{HH}$. We notice that the divergence of the economy is discontinuous in the right direction. After a while wages will turn so high that they will account for practically 1008 of the costs of producing H. At this point real wages become constant and emloyment and home good output stabilize while nominal wages continue their upward trend.

The conclusion coming out from this analysis is twofold:

(a) The original $\mathrm{R}-\mathrm{T}$ model is considerably weakened if we allow for some plausible response in wages, because by becoming unstable it can not be used for comparative static purposes.

(b) The fundamental result of $\mathrm{K}-\mathrm{T}$ remains true, in the sense that a devaluation has perverse effects. But this time the contraction persists through time driving downwards both output and employment. 
Figure 1

WAGE DYNAMICS AND INSTABILITY

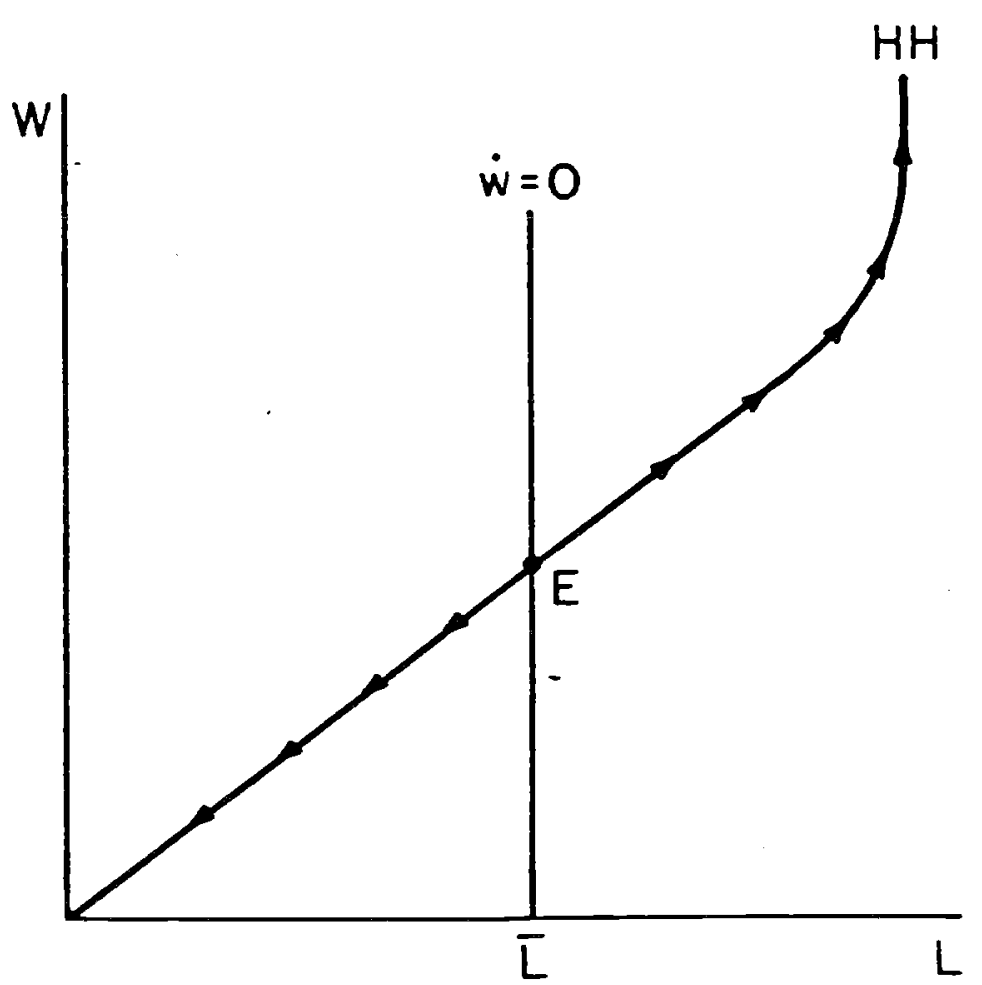


4. Wage and export dynamics.

4.1. The new setup.

A most natural way to search for stabilizing forces would be to relax the $R-T$ assumption of a fixed supply of exports determined by existing capacity, which has been carried on until now. Indeed, available international studies such as Sachs (1982b, 1983) and Larrain (1985) show a significant, negative response of employment (and thus of output) to real wages in the tradeable sector for both industrialized and developing countries. The fact that the employment response is contemporaneous suggests that a devaluation, operating through a reduction in real wages, has an effect in the supply of tradeable goods even in the short run.

A straightforward extension of the $\mathrm{K}-\mathrm{T}$ model to allow for export response to prices in a static framework will simply introduce another source of ambiguity in the devaluation effect on real income. Our attempt is, however, to study the dynamic adjustment of the economy after a shock. We will assume accordingly that exports are neither in fixed supply, nor that they adjust instantaneously; rather, they will respond through time to movements in the real wage. An adjustment pattern such as this can be formally derived from an intertemporal profit-maximizing firm facing adjustment costs in the hiring and firing of labor. This strategy has not been pursued to keep the model as simple as possible, avoiding expectational issues.

Let the long run supply of exportable goods $\left(x^{*}\right)$ respond to unit profits in the standard form 


$$
\begin{aligned}
\text { (11) } x^{*} & =\theta\left(P_{x}^{*} e-a_{1} w\right) & \theta>0 & \text { for }\left(P_{x}^{*} e-a_{1 x} w\right)>0 \\
& =0 & & \text { for }\left(P_{x}^{*} e-a_{1} w\right)<0
\end{aligned}
$$

The above equation is ad-hoc in one important respect. In principle, output should respond not only to the current level of profits but also to the entire path of future profits. This limitation becomes serious in an economy where nominal wages quickly respond to price changes, 9 but looses importance the slower wages catch up with inflation. Available empirical evidence tends to support this latter view. In a study of 24 devaluations for the period 1953-66, and including most major exchange rate changes in developing countries, Cooper (1971b) found that "...twelve months after devaluation.... general wholesale prices will have risen less than this, consumer prices will have risen by about the same as wholesale prices and, except where devaluations are small, manufacturing wages will have risen by less than consumer prices... Thus nonwage income of employed factors -mostly profits and rents- show an increase in real terms a year later and it is this increase that provides the incentive for the necessary reallocation of resources..."10 Larrain (1985) has also presented evidence for 12 developing countries indicating that devaluations, except when small, tend to reduce the product wage in the manufacturing and mining sectors.

$$
\text { In our scenario the level of } x \text { is fixed on impact; its response th- }
$$

rough time is given by ${ }^{11}$

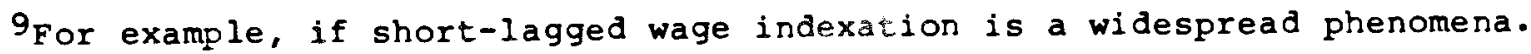

10 Cooper $(1971 b)$, p. $27-28$.

${ }^{1}$ It is immediate to se that a function like $\Psi\left\{\left(X^{*}-X\right) / X^{*}\right\}$, which has the sa-

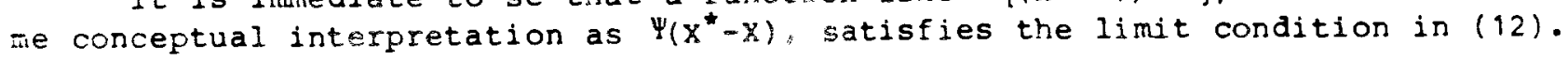




$$
\begin{aligned}
& \text { (12) } \dot{x}=Y\left(x^{*}-x\right) \quad \text { if } x>0 \\
& =\max \left[0, \psi\left(x^{\star}-x\right)\right] \text { if } x=0 \\
& \text { with } \Psi \cdot\rangle, \Psi(0)=0 \\
& \text { y' } 0 \text { for } x^{*}>x \\
& \Psi_{1}<0 \text { for } x * x \\
& \lim _{x \rightarrow 0} \Psi\left(x^{*}-x\right)=-\infty
\end{aligned}
$$

The parameter of export response ( $\left.\Psi^{\prime}\right)$ has been specified as an increasing function of the difference between the current and desired level of exports in a similar way as the quantity response mechanisms used by Beckman and Ryder (1969) and Mas-Colell (1985). Thus, the more a devaluation increases perunit profit, the faster will exports increase towards their long run equilibrium. On the other hand, if profits are squeezed by wage increases so that $\left(X^{*}-X\right)$ turns negative, exports will contract increasingly faster as this gap widens. When profits are down to zero or turn negative export production will tend to stop altogether. This pattern of response is illustrated in figure 2 .

$$
\text { Replacing (11) in (12) we get }
$$

(13) $\dot{x}=\Psi\left\{\theta\left(P_{x}{ }^{\star} e-a_{1} w\right)-x\right\}$

From (13) we can start studying the Jacobian matrix of the dynamic system

(14) $\dot{\partial x} / \partial x=-\psi_{1}$

We have not used it for reasons of tractability. 
Figure 2

EXPORT ADJUSTMENT

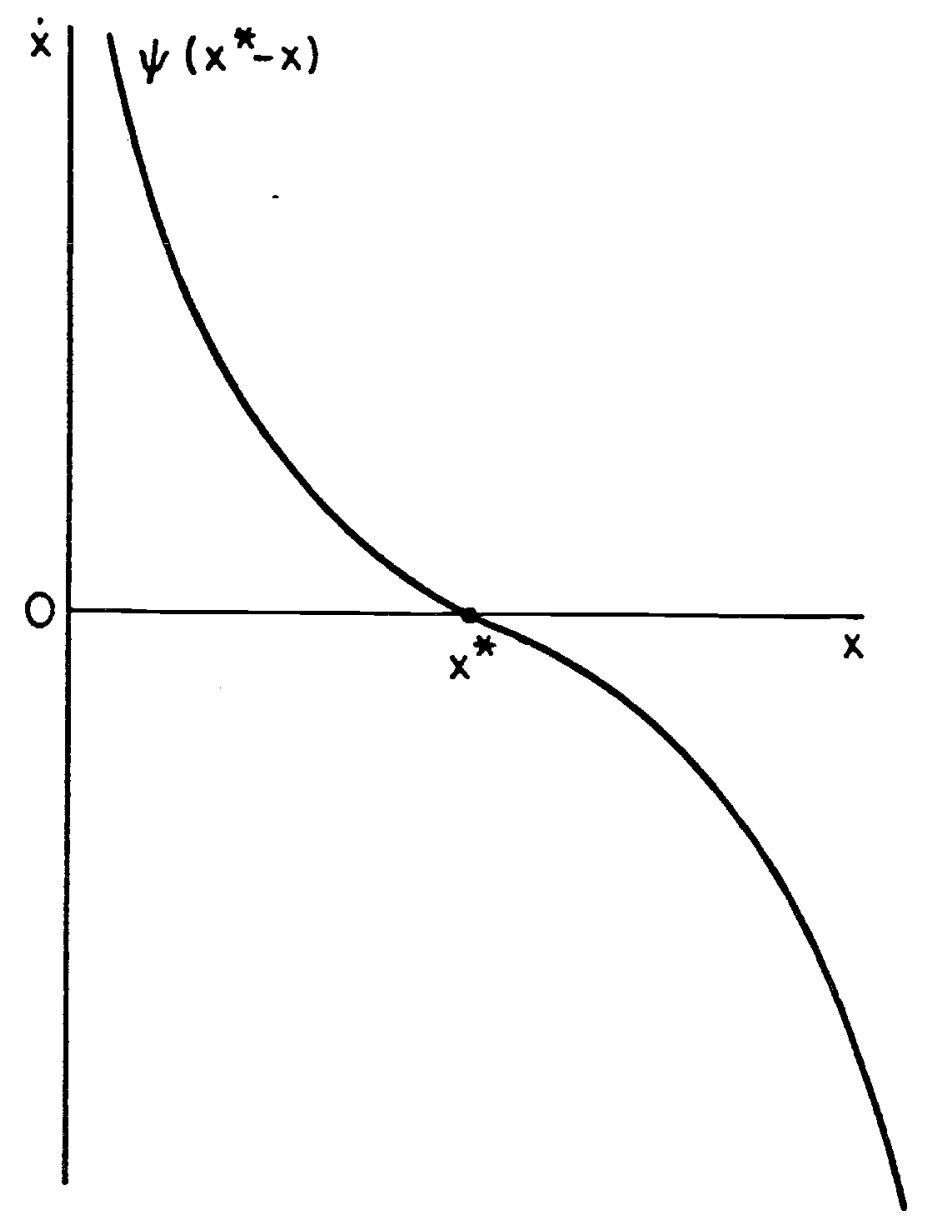


(15) $\partial \dot{x} / \partial_{w}=-\psi_{1} \theta_{1 x}$

Wage dynamics are specified starting from equation (8); after some computations we arrive to

(16) $\frac{\partial_{w}^{*}}{\partial_{w}}=\frac{\phi^{\prime} a_{1 h}(1+z)}{D_{1} P_{h}}\left\{\left(\gamma_{w}-\gamma_{I}\right) x_{0} "+a_{1 x}\left(\gamma_{w} M_{m} * e-\gamma_{I} X P_{x}^{*} e\right)\right\}$

where

$D_{1}=\left\{a_{1 h} w\left(\left(1-\gamma_{w}\right)+z\left(1-\gamma_{I}\right)\right)+a_{m h} P_{m}^{*} e\left(1+z\left(1-\gamma_{I}\right)\right)\right\}$

$K_{0} "=a_{I x} \times a_{m h} P_{m}{ }^{\star} e$

From (8) and the employment identity

(17) $\left.\frac{\partial_{w}^{*}}{\partial x}=\phi^{\prime} \frac{a_{1 h}}{D_{1}}\left(\left(\gamma_{w}-\gamma_{I}\right) a_{1 x} w+\gamma_{I} P_{x}^{*} e\right)+a_{1 x}\right\}$

Both expressions (16) and (17) are positive under the current working assumptions.

4.j. Iocal stability.

We have thus two downward sloping schedules in $(X, w)$ space $(\dot{X}=0$ and $\dot{w}=0$ ) whose relative slopes will presumably be related to the issue of stability. Writing the dynamic system in matrix form around the steady state

(18) $\left|\begin{array}{c}\dot{x} \\ \dot{w}\end{array}\right|=z\left|\begin{array}{c}x-x^{*} \\ w-w^{*}\end{array}\right|$

Where $\mathrm{z}$ is the Jacobian or transition matrix whose elements are (14), (15), (16) and (17). Local stability in this predetermined-variables model re- 
quires both trace(z):0 and determinant(z)>0 to guarantee that the real part of the eigenvalues of $z$ will be negative.

$$
\begin{aligned}
& \text { (19) } \operatorname{tr}(z)=-Y_{1}+\frac{\phi^{\prime} a_{1 h}(1+z)}{D_{\mathcal{Y}} P_{h}}\left\{\left(X_{w}-Y_{Y}\right) a_{1 x} X a_{m h} P_{m}+a_{I h}\left(X_{w} M P_{m}-Y_{I} X P_{x}\right)\right\} \\
& \text { (20) } \operatorname{det}(z)=\Psi^{\prime} \phi^{\prime}\left\{\theta_{a_{1 x}}\left\{\left(a_{I h} / D_{1}\right)\left(\left(\gamma_{w}-Y_{I}\right) a_{1 x^{w}}+Y_{I} P_{X}\right)+a_{1 x}\right\}\right. \\
& \left.\frac{-a_{1 h}(1+z)}{D_{1} P_{h}}\left\{\left(\gamma_{w}-Y_{I}\right) a_{1 x} X a_{m h} P_{m}+a_{1 h}\left(\gamma_{w} M P_{m}-Y_{r} X P_{X}\right)\right\}\right\}
\end{aligned}
$$

where $\mathbf{Y}^{\prime}$ has been evaluated at steady state.

Even though both (19) and (20) have ambiguous signs, there are three parameters which play a key role in the above expressions: (a) The speed of adjustment of exports toward their long run level ( $\left.\Psi^{\prime}\right)$; the higher this value, the more likely that the trace condition will be satisfied, although it has no effect on the sign of the determinant.

(b) The parameter of wage adjustment ( $\phi^{\prime}$ ) influences only the trace; the higher it is, the more likely the unstable outcome occurs.

From (19) the exact relationship between these two coefficients and the parameters of the model for a stable trace condition is:

$$
\Psi^{\prime}>\frac{\phi^{\prime} a_{I h}(1+z)}{D_{1} P_{h}}\left\{\left(\gamma_{w}-Y_{I}\right) a_{l x} X a_{m h} P_{m}+a_{I h}\left(\gamma_{w} M P_{m}-Y_{I} X P_{x}\right)\right\}
$$

(c) The long run response of exports to price incentives ( $\theta$ ), even if it plays no role in the trace, the higher its value the more likely that the determinant will be positive. The exact relationship for this condition to be satisfied is: 
(22) $\theta>\frac{\left\{\left(\gamma_{w}-Y_{I}\right) a_{1 x} X a_{m h} P_{m}+a_{1 h}\left(Y_{w} M P_{m}-Y_{I} X P_{x}\right)\right\}}{\left\{a_{1 h}\left(\left(\gamma_{w}-Y_{I}\right) a_{1 X}{ }^{w+} Y_{I} P_{X}\right)+a_{1 x} D_{1}\right\}}$

Therefore, stability requires both a fast adjustment of exports and a high long run response of them to price incentives. That the source of potential instability arises from the interaction of a demand determined home good sector and the Phillips curve is also clear. Indeed, if the contractionary effects from a devaluation coming from the different marginal propensities to consume and the initial trade deficit were not present, conditions (21) and (22) get immediately satisfied.

We also notice that, as could be expected, the relative slopes of the two loci and the stability issue are not independent. From equations $(16),(18)$ and (22) it is apparent that the value of $\theta$ required to make the determinant positive is exactly the same one needed for the $\dot{w}=0$ locus to be steeper than $\dot{x}=0$. In figure 3 the two possible cases are presented. From the transition matrix $z$ we can draw the corresponding arrows of motion and study the direction of forces implied by the resulting vectors in each of the four regions. This confirms our earlier discussion; when $\dot{x}=0$ is steeper than $\dot{w}=0$ (case of a low $\theta$ ) a clearly divergent path when away of equilibrium arises. On the other hand, when $\dot{x}=0$ is flatter than the wage schedule the system presents a counterclockwise movement.

What is the economics out of these stability conditions? We recall that a devaluation, by cutting real wages, has both a contractionary effect in 
Figure 3

WAGE AND EXPORT ADJUSTMENT:

$\mathrm{HIGH}$ (A) AND LOW (B) LONG-RUN RESPONSE OF EXPORTS

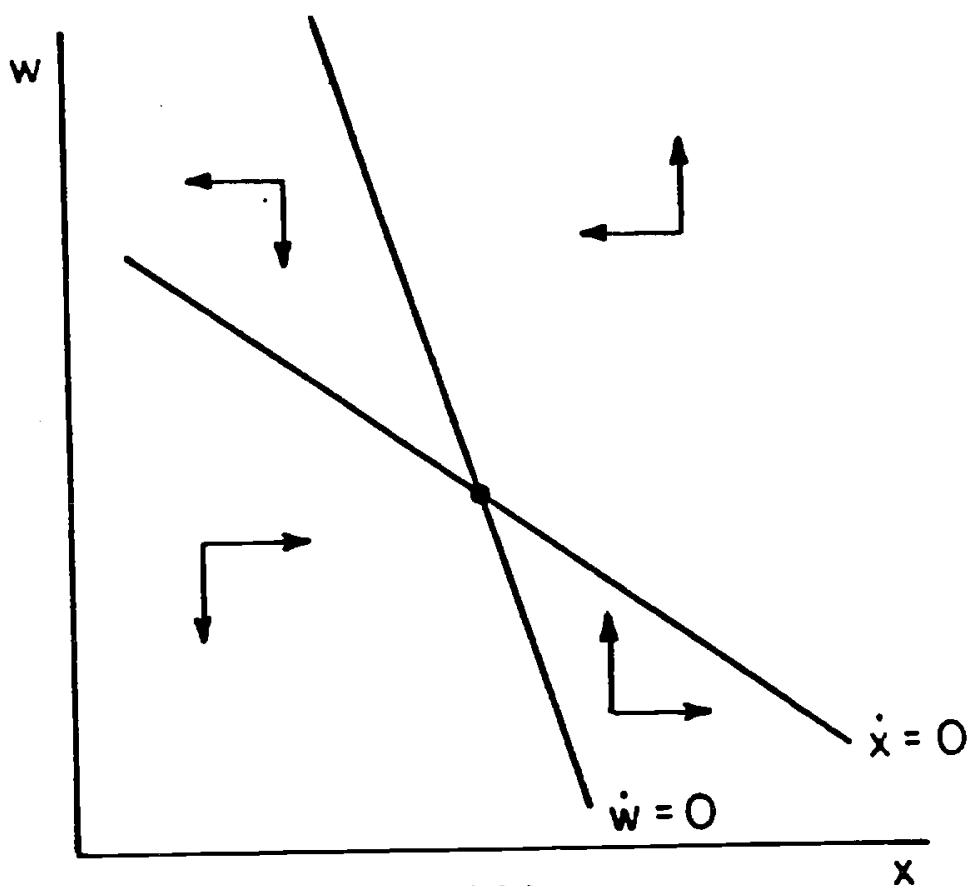

(A)

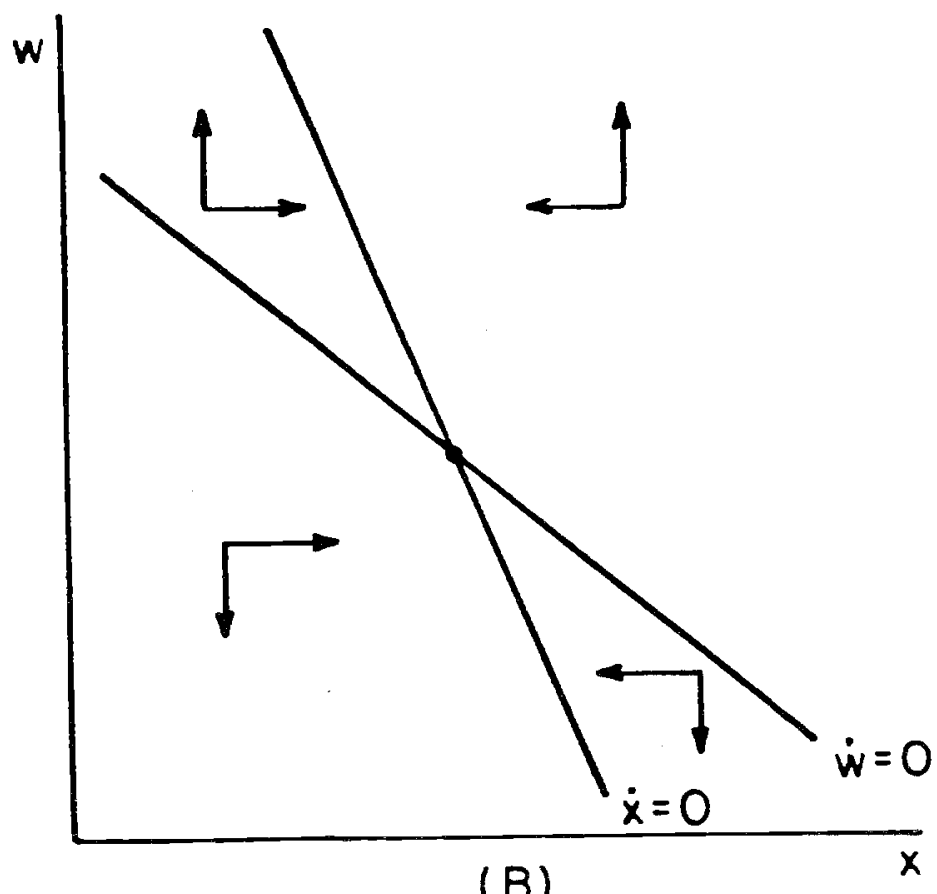

(B) 
the demand for home goods and an expansionary influence on exports through time. In figure $3 \mathrm{~B}$ the long run export response is not big enough and the contractionary effect dominates; in this case unemployment will increase putting downward pressure on the wage rate and leading to the unstable outcome. However, $\theta$ being sufficiently high to guarantee that the relative slopes are correct as in figure 4A is not enough for a stable outcome. From now on we will concentrate in the case in which stability depends on the relative speeds of adjustment of wages and exports (the trace condition), assuming the determinant to be positive and thus ruling out case $3 B$.

Since the trace is now the sole condition which determines stability, we can distinguish two possible cases from equation (21) which will be illustrated graphically and conceptually with the help of figure 4.

(i) If exports adjust slowly relative to wages condition (21) will not be satisfied and we can expect the unstable outcome. This situation may be visualized by starting at a point like $A$ in figure 4 , where the wage is low enough to encourage the export sector and unemployment prevails. The economy begins moving southeast through the dotted line with the wage declining due to unemployment and exports moving slowly upwards. At $B$ the wage stops moving (the natural level of unemployment is reached), but there still remain incentives to expand exports; this leads to overemployment and w starts rising. At $c$ exports stop growing but overemployment keeps increasing wages. Now, if exports would respond fast we will soon move in the horizontal direction; but this is not the case and the adjustment is more upwards than to the left. Continuing the analysis it is easy to 
Figure 4

DIFFERENT SPEEDS OF ADJUSTMENT

IN EXPORTS RELATIVE TO WAGES

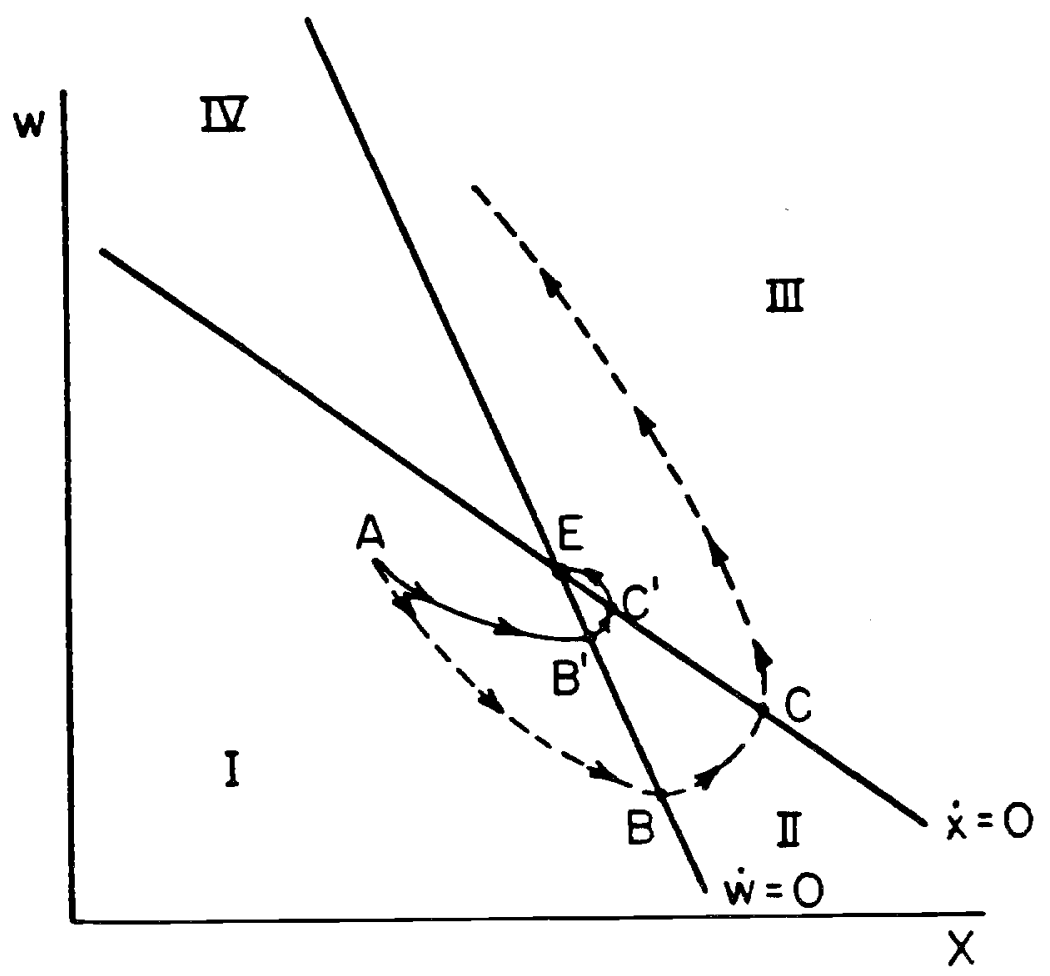


see that the system diverges. (ii) Conversely, if exports are fast to react relative to wages condition (29) will be satisfied and local stability is guaranteed. Let us start again from point $A$; this time the low wage makes exports expand rapidly and the economy moves from $A$ to $B$ ' through the solid line. Once $w$ crosses the $\dot{x}=0$ level (above $C^{\prime}$ ) exports take a small period of time to contract. We quickly converge to equilibrium through the solid path $A B^{\prime} C^{\prime} E$.

Notice that in the adjustment process the home good sector is also reacting. In region $I$ while wages fall employment is expanding because exports increase; the net effect on labor income and thus on the home good sector is anbiguous. Region II, with exports, wages and employment growing is a boom period for the whole economy. On the contrary, area IV is a period of generalized depression. The situation in the four regions is sumnarized in Table 1.

\section{TABLE 1}

\begin{tabular}{|c|c|c|c|c|c|}
\hline & Region & I & II & III & IV \\
\hline$\frac{\text { sector }}{\text { Home goods }}$ & & & & & \\
\hline Exports & & expand & $\begin{array}{l}\text { expand } \\
\text { expand }\end{array}$ & $\begin{array}{c}? \\
\text { contract }\end{array}$ & $\begin{array}{l}\text { contract } \\
\text { contract }\end{array}$ \\
\hline
\end{tabular}

\subsection{Towards global stability.}

So far, we have just analyzed local stability around the steady state and concluded that only if exports adjust fast enough relative to wages the economy will go back to equilibrium when a shock disrupts it. In this section we will show that even if this condition is not satisfied the system has forces that will drive it to a stable cycle at some distance of the equilibrium. Thus, 
the fact that the economy is not locally stable around steady state does not mean that it will explode through time.

It is clear that if the model were totally linear, local and global stability conclusions will necessarily coincide. Indeed, local dynamic analysis is done by linearizing around steady state which is obviously unnecessary when the system is already linear. Our model, however, has two sources of nonlinearity as defined: on the one hand it is defined only for positive values of $w$ and $x$, and on the other, the speed of adjustment of exports ( $\psi^{\prime}$ ) increases the farther away is the current level with respect to the desired one. The idea behind this formulation is that if we start from equilibrium, as wages fall (increase) the export sector becomes increasingly profitable (unprofitable) for given exchange rate and world price, and thus exports would react faster.

We are then interested in studying the case where local instability occurs $(\operatorname{tr}(z)>0, \operatorname{det}(z)>0)$, but in which export responsiveness grows with the distance from equilibrium. Suppose for a moment that the value of $\Psi^{\prime}$ relative to the other parameters of the model is such that the trace at equilibrium is very close to zero (i.e. the system is borderline stable or unstable). Then we can appeal to Hopf bifurcation theory (see Mas-colell (1985))12 and obtain the existence of a Hopf bifurcation cycle as the economy goes from stable to unstable (or viceversa). Technically, it is necessary that the trace has some nonli-

12 For an advanced mathematical treatment on Hopf bifurcation see Hassard, Kazarinoff and wan (1981). 
nearity embedded, which is guaranteed in our model by the shape of the export adjustment function. It should be kept in mind, as Mas-colell (1985) remarks, that Hopf bifurcation is still a local analysis of dynamics in the neighborhood of the steady state, since the trace condition looses its meaning when going away of equilibrium. A plausible form of the Hopf cycle is shown in figure 5 .

The appropriate study of the stability properties of the Hopf cycle involves examining third, fourth and even higher order derivatives of the functions. This task may be perfectly justified for a mathematics study, but lacks any significant economic meaning and will not be attempted. Getting the correct stability conditions by ill-grounded assumptions about the $\Psi$ and $\phi$ functions will not improve our understanding about how the economy works.

Rather than going in that direction we will go in another, less restrictive way. An attempt will be made to show that the system has at least one stable cycle by using the poincare-Bendixson theorem, valid for global dynamic analysis and with no restrictions in the size of the trace.13 Following Beckman and Ryder (1969), Benassy (1984) and Mas-colell (1985) the conditions for the existence of this type of cycle are:

(i) The long run equilibrium is unstable.

(ii) There exists a bounded, invariant and simply connected region.

\section{Definitions:}

(D.1) Invariant region is one which is absorbing in itself, that is, every point

13 The analysis of Poincare-Bendixson is carried through for the case in which the equilibrium is unique. If the global extension of condition (22) is met, uniqueness unambiguously holds. However, $(22)$ is sufficient but not necessary for a unique equilibrium, and thus stronger than we need. 
Figure 5

HOPF BIFURCATION CYCLE

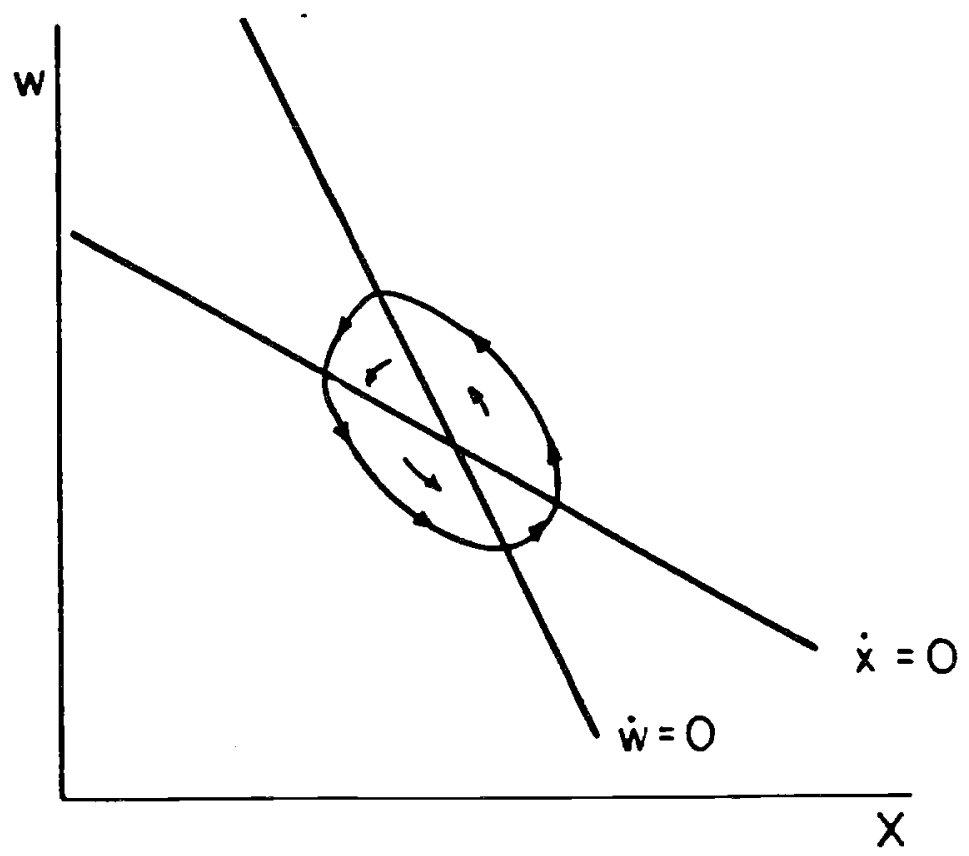


starting inside the region will remain inside it.

(D.2) Globally absorbing is a region where every point will enter in finite time (either starting inside or outside it).

(D.3) Informally, the simply connectedness condition means that the region has no holes inside it.

Theorem: The dynamic system defined in equations (8) and (12), under the conditions in (8), (11), and (12) contains at least one stable cycle.

Proof: To demonstrate the theorem we must show that the requirements (i) and (ii) for a Poincare-Bendixson cycle are met. This is done below.

Condition (i) is immediately met when the trace is negative around the steady state, which is the case we are analyzing.

To show condition ( $i$ ) we need to construct a region with the desired characteristics, which will be done with the help of figure 6 . We first notice that the two axes are natural boundaries since the system is only defined for positive $w$ and $x$. Let us start in a point like $A$, to the right of the intersection between the $\dot{x}=0$ locus and the horizontal axis, where the level of $x$ is higher than its equilibrium. The dynamics of the model start moving the economy north-west, with wages rising and exports contracting. As wages rise the export sector moves farther away from equilibrium, speeding up its own reaction; because export contraction finally dominates over the upward trend in wages the economy moves in a path like $A B$, collapsing in the vertical axis. By the conditions in (8) and (12) the point of intersection of this trajectory and the wage axis can be -at the most-at $c$. Exports are there at equilibrium but forces still 
Figure 6

POI NCARE-BENDIXSON CYCLE

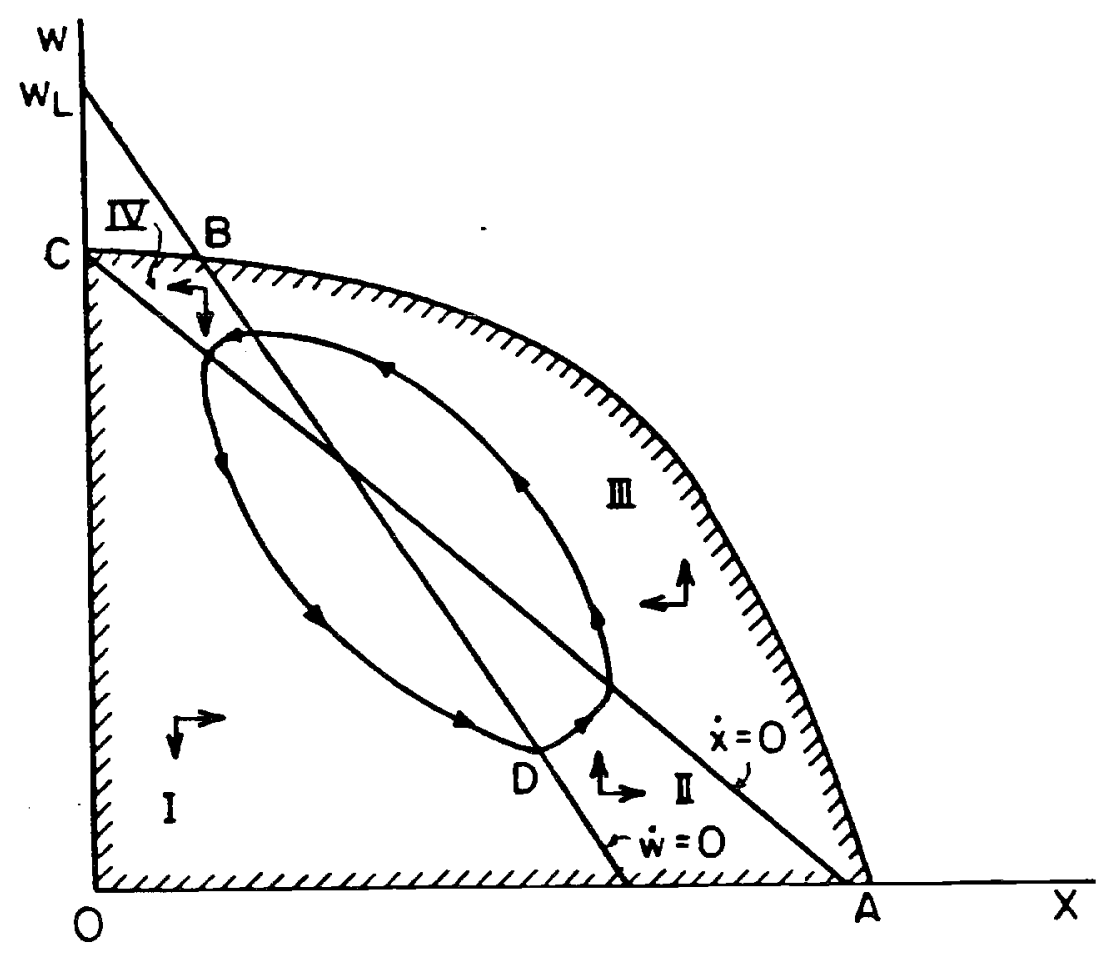


exist in the economy to decrease wages. Once point $c$ is crossed exports are again profitable and, with wages falling, the movement is south-east. It becomes then clear that $O A B C O$ is a bounded, invariant and simply connected region inside of which there exists at least one stable limit cycle as figure 6 shows. This completes the proof of the theorem.

The region $O A B C O$ is not globally absorbing since, for example, points starting above wl will not collapse into it within a finite time. Rather, those trajectories will touch the vertical axis above $w_{1}$ and will remain at the level of $x=0$ with nominal wages steadily increasing. Real wages, though, will converge to a constant value as labor approaches 1008 of the costs of producing the home good. At that point all real variables in the model will have reached stationary values.

Combining the Hopf bifurcation (HB) and the Poincare-Bendixson (PB) analyses we have three possible cases:

(i) If the HB cycle exists and is stable, then there exists at least one stable cycle in the system, since it may happen that $P B$ and $H B$ coincide.

(ii) If the $\mathrm{HB}$ cycle exists and is unstable, there exists at least one other stable cycle, since $P B$ is always stable. The minimum number of cycles in this situation is two: one stable and one unstable.

(iii) If the $\mathrm{HB}$ cycle does not exist, there is at least one stable cycle in the system $(\mathrm{PB})$.

Notice that a large value of $\Psi^{\prime \prime}$ (fast export adjustment) is not
enough to generate cycles. If in addition $\Psi^{\prime \prime}=0$ the system will be globally sta- 
ble, provided condition (29) is met, but no cycles will occur.

The theoretical results analyzed are an adequate representation of the situation lived by many third world nations. In particular, Iatin-American countries typically undergo cycles in which periods of slow overall growth, booms and recessions alternate. This is in the spirit of the predictions of our model, as illustrated in the four regions of figure 6 . If we start at point $D$, the economy is beginning a boom period (region II) with both exports and wages expanding. The boom runs out of steam because real wages get too high, squeezing exports (III) and a recession is ad-portas. The farther away from equilibrium with wages rising, the faster exports contract; at some point wages can no longer keep rising and unemployment starts developing. A deep recession then develops with wages and exports falling (IV). After a while wages have fallen enough and exports are again profitable (region $I$ ); wages will continue falling until the export sector has expanded enough. When the economy reaches point $D$ a full cycle has been completed and the process is about to start again.

It is important to notice that the existence of cycles with large amplitudes can only be accounted for by Poincare-Bendixson type analysis. Hopf theory is only a local phenomenon occurring in the vicinity of the steady state which can not explain wide fluctuations.

This analysis suggests that for a good number of developing countries neither neo-classical nor structuralist models may be applicable. If the supplyresponse forces in the economy are weak enough around the steady state the long run equilibrium will never be reached. This does not imply that the economy will 
diverge towards zero output and employment, which would happen if wages keep faling and supply does not react. The outcome is likely to be somewhere in the middle, with the economy undergoing a stable cycle at some distance from the equilibrium.

5. Conclusion.

This paper has been focused on the potential contractionary effects of a devaluation and the subsequent dynamic adjustment of the economy after it. The starting point is Krugman and Taylor (1978) (K-T) who emphasize the redistribution effects of a devaluation from an initial trade deficit, drawing on earlier contributions by Diaz-Alejandro (1963, 1965), Robinson (1947), Hirschman (1949) and cooper (1979a). Their main conclusion is that a devaluation is unarnbiguously contractionary, a hardly surprising result given that exports are in fixed supply and there is neither substitution in production nor in consumption in their model.

Dynamics are introduced in the model by letting wages sluggishly adjust through time. In this scenario the devaluation continues being contractionary, but in addition the equilibrium is shown to be unstable because the initial reduction in real wages decreases demand for home goods which in turn reduce employment, bringing the real wage further down; there are no forces in the model to stop this downward trend.

A more realistic scenario is then set with exports adjusting through time in addition to wages. This extension is suggested by empirical studies such 
as Sachs (1982b, 1983) and Larrain (1985) which show a contemporaneous response of employment (and thus of output) to real wages in the tradeable sector for a group of industrialized and developing countries. In this framework, local stability around steady state is achieved both with a high long run response of exports to price incentives and with a higher speed of adjustment in exports than wages. Because the model has some nonlinearities embedded, the existence of local instability does not imply global instability. Indeed, when exports adjust slowly in relation to wages around the steady state, the economy is locally unstable, while at the same time it undergoes at least one stable cycle. In particular, conditions are discussed under which a Hopf bifurcation cycle and a Poincare-Bendixson limit cycle exist.

The key element explaining the existence of a Poincare-Bendixson cycle, the one more relevant to explain wide fluctuations, is the pattern of export response, whose velocity increases (relative to wages) when going away from equilibrium. Thus, if we consider a devaluation which is contractionary on impact, at some distance of steady state the expansionary forces coming from export reaction to increased profitability will be strong enough to offset the negative influences arising from income redistribution and the initial trade deficit. This stops the divergent path of the economy.

This analysis seems an appropriate representation of the reality in a number of developing countries where neither neoclassical nor structuralist models seem fully appliccable. The supply-response forces may be weak enough around steady state so that long run equilibrium will never be reached. This 
does not imply that the economy will diverge through time towards lower levels of output and employment, which would happen if wages keep falling and supply does not react. Rather, third world countries typically undergo periods of slow growth interrupted by booms and depressions, the characteristics of the cycle described in this paper. 


\section{REFERENCES}

f.lexander, S. (1952) "The effects of devaluation on a trade balance." International Monetary Fund Staff Papers, p. 263-278.

Beckman, M. and H. Ryder (1969) "Simultaneous price and quantity adjustment in a single market". Econometrica, p. 470-484.

Eenassy, J.P. (1984) "A non-Walrasian model of the business cycle." Journal of Economic Behavior and Organization, p. 77-89.

Connolly, M. and D. Taylor (1976) "Testing the monetary approach to devaluation in developping countries." Journal of Political Economy, p. 849-859.

cooper, R. (1971a) "Devaluation and aggregate demand in aid-receiving countries." In J. Bhagwati et al. (eds.) "Trade, balance of payments and growth."

Cooper, R. (1971b) "Currency devaluation in developing countries." Essays in International Finance \#86, Princeton University.

Diaz-Alejandro, C. (1963) "A note on the impact of devaluation and the redistributive effect." Journal of Political Economy, p. 577-580.

Diaz-Alejandro, C. (1965) "Exchange rate devaluation in a semi-industrialized country." M.I.T. Press.

Dornbusch, R. (1974) "Real and monetary aspects of the effects of exchange rate changes." In R. Aliber (ed.) "National monetary policies and the international financial system." University of Chicago Press.

Dornbusch, R. (1975) "A portfolio balance model of the open economy." Journal of Monetary Economics, p. 1-20.

Dornbusch, R. (1976) "Exchange rates and fiscal policy in a popular model of international trade." American Economic Review, p. 859-871.

Jornbusch, R. and M. Mussa (1975) "Consumption, real balances and the hoarding function." International Economic Review, p. 415-421.

Gylfasson, T. and M. Schmid (1983) "Do devaluations cause stagflation?" Canadian Journal of Economics, p. 641-654.

Hanson, J. (1983) "Contractionary devaluation, substitution in production and consumption and the role of the labor market." Journal of International Economics, p. 179-189.

Harberger, A. (1950) "Currency depreciation, income and the balance of trade." Journal of Political Economy, p. 47-60.

Eassard, B., N. Kazarinoff and Y. Wan (1981) "Theory and applications of Hopf bifurcation." London Mathematical Society Lecture Notes Series, 49, Cambridge University Press. 
Hirschman, A. (1949) "Devaluation and the trade balance: a note." Review of Economics and statistics, p. 50-53.

Hume, D. (1752) "On the balance of trade." Reprinted in R. Cooper (ed.) "International Finance." (1969), Penguin.

Johnson, H. (1977) "The monetary approach to the balance of payments." Journal of International Economics, p. 251-268.

Krueger, A. (1978) "Liberalization attempts and consequences." Ballinger.

Krugman, P. and L. Taylor (1978) "Contractionary effects of devaluation." Journal of International Economics, p. 445-456.

Larrain, F. (1985) "Essays on the exchange rate and economic activity in developing countries". Unpublished Ph.D. Dissertation, Harvara University.

Laursen, S. and L. Metzler (1950) "Flexible exchange rates and the theory of employment." Review of Economics and Statistics, p. 251-299.

Lerner, A. (1944) "The economics of control." Macmillan, New York.

Mas-Colell, A. (1985) "Notes on price and quantity tatonnement dynaIn H. Sonnenschein and $H$. Weinberger (eds.)

"Price-quantity dynamics." Springer Berlack Lecture Notes.

Marshal1, A. (1923) "Money, credit and commerce." Macmillan, London.

Obstfeld, M. (1982) "Aggregate spending and the terms of trade: is there a Laursen-Metzler effect?" Quarterly Journal of Economics, p. 251-270. Robinson, J. (1947) "Essays in the theory of employment." Basil Blackwell, Ox-
ford. Sachs, J. (1981) "The current account and macroeconomic adjustment in the
1970s." Brookings Papers on Economic Activity: 1, p. 201-268.

Sachs, J. (1982a) "The current account in the macroeconomic adjustment process." Scandinavian Journal of Economics, p. 147-159.

Sachs, J. (1982b) "Comment on the employment-real wage relationship: an international study." Mimeo, Harvard University. Sachs, J. (1983) "Real wages and unemployment in the OECD countries." Brookings
Papers on Economic Activity: 1, p. 255-289.

Svensson, L. and A. Razin (1983) "The terms of trade and the current account: the Harberger-Laursen-Metzler effect." Journal of Political Economy,
p. 97-125. 